\title{
Effects of Graded Reading on Middle School Students' Reading Comprehension
}

\author{
Yiyang $\mathrm{Zou}^{1}$ \& Shaoyun Long ${ }^{1}$ \\ ${ }^{1}$ School of Foreign Languages, Jiangxi Normal University, Nanchang, China \\ Correspondence: Yiyang Zou, 99\#Ziyang Road, Jiangxi Normal University, Nanchang, Jiangxi Province, China. \\ E-mail: 993403302@qq.com
}

Received: July 21, 2019 Accepted: August 19, 2019 Online Published: August 26, 2019

doi:10.5539/ells.v9n3p39 URL: https://doi.org/10.5539/ells.v9n3p39

\begin{abstract}
Reading is a key and focus in the process of students' English learning (Chen \& Jiang, 2010). Research shows that graded reading materials based on students' reading ability will help students to improve their reading level step by step (Stern \& Dich, 2017). The paper here explores the effects on middle school students' reading comprehension so as to find whether graded reading can cultivate students' positive reading attitude and improve their reading level or not, using qualitative and quantitative research methods. Results reveal that because of the rich content and active class atmosphere, graded reading is conductive to arouse students' reading interest and cultivate their positive reading attitude, and the graded reading materials adapted to students' current reading ability can reduce students' anxiety, improve their reading level effectively as well. In conclusion, graded reading has certain guiding significance for middle school English reading teaching.
\end{abstract}

Keywords: graded reading, reading attitude, reading level

\section{Research Background}

Graded reading can trace to Charles and Mary Lamb's Tales from Shakespeare (1807). In graded reading, the reading materials are selected according to the competence of the learner, the vocabulary and syntax are controlled to suit the learner's English ability, and the difficulty of each series book is gradually increased, which can meet the needs of every learners (Azumuddin \& Zuraina, 2017). But in the current reading teaching, students have been used to teachers' directly instil teaching method. Thus, learners' interest in reading learning is relatively lower while anxiety is higher (Ramirez, Fries, \& Gunderson, 2018). Therefore, this paper wants to explore whether graded reading can stimulate students' reading interest and improve their reading level or not.

\section{Literature Review}

In this section, the definition of graded reading, theoretical basis, foreign and domestic researches of English reading, limitations of present study will be introduced.

\subsection{Definition of Graded Reading}

Graded reading refers to a kind of textbook of varying levels of difficulty, intended to be used by students to read or learning a foreign language (Gillian, 2012). In the early 19th century, the idea of graded reading was put forward by foreign scholars, and then it developed abroad, especially in Europe and America. At the same time, a variety of graded reading standard system also emerged and gradually improved.

\subsection{Theoretical Foundations}

\subsubsection{Affective Filter Hypothesis}

The affective filter hypothesis was developed by Krashen in the 1970s, who believed that emotional variables such as self confidence, anxiety, and motivation were associated with second-language acquisition. In the process of language learning, affective factors may promote or hinder language input, he regards this affective factor as a filter. In language teaching, the positive or negative attitude of language learners has a direct impact on the acceptance of language input. If learners have clear goals, high motivation, high self-confidence, moderate anxiety, then weak affective filter will be established, and vice versa. In language acquisition, if the emotional filter is too strong, the brain will form obstacles, language input will encounter hindrance. If the affective filter is reduced, the comprehensible language input can enter the language acquisition mechanism 
smoothly, speeds up the language acquisition process. Only reduces the affective filter, eliminates the student's psychological barrier, students can study effectively.

\subsubsection{Schema Theory}

The schema theory was put forward by Bartlett in 1932. He pointed out that schema refers to a proactive organizing role of past reactions or past experiences, which not only enables individual components to act, but also organizes and integrates them as a whole. What one learns must be some abstract system or scheme, rather than a rambling catalogue of simple knowledge. According to Schema theory, readers' reading ability and comprehension of materials depend on three schemata: linguistic schemata, content schemata and formal schemata. Language schemata refers to the internal knowledge of vocabulary, grammar and acquisition, while content schemata refer to the familiarity with the topic and background knowledge. Formal schema refers to the reader's understanding of the layout of different articles, that is, the reader's familiarity with the articles.

\subsection{Foreign Researches on English Reading}

In the 1960s, more and more researchers began to study English reading. In 1972, Gough proposed a bottom-up approach to reading. He saw reading as a decoding process, readers read from basic language units such as letters and words to top-level language units such as paragraphs and chapters. In the early 1970s, Gudeman's "top-down" model of linguistic psychology was called the "linguistic psychology" model or the "Gudeman" model. In 1977, Rummelhardt published the interactive reading model and proposed his interactive theory model On the basis of Gudeman model and Gough Model, reading is actually a complicated interactive process of vocabulary, semantics, syntax and context (Rumelhart, 1977). As for reading attitude, the researchers believe that reading attitude is related to the individual's reading experience, which may vary according to reading purpose and reading environment. The research on the influence of creative literacy classroom activities on the acquisition of English as a foreign language shows that there is a significant interaction between creative literacy classroom activities and English reading attitudes. Creative English classroom activities can improve students' reading attitude. Children's attitudes formed in early reading teaching have a great influence on their later reading. Children's feelings about reading are ultimately related to their success in reading. Because of the relationship between positive reading attitudes and academic achievement of school-age children, teachers need to help students develop positive reading attitudes (Chowbw \& Chuibh, 2017).

\subsection{Domestic Researches on English Reading}

Wen's research report in 1996 pointed out that good English readers are indexed by their intrinsic motivation. At the same time, many Chinese middle school English teachers' surveys show that many students have lost interest, confidence and motivation in English reading due to the deep-rooted anxiety in the process of English reading. Xia's research report reveals that there is a certain correlation between reading behavior, reading attitude and reading achievement. In her research, reading behavior is an intermediary between reading attitude and reading achievement (Xia, 2017). Zeng pointed out that reading strategies were positively correlated with students' English learning achievements, and the experimental class not only improved in reading efficiency and learning achievements, but also had a higher growth rate than the control class. In addition, students in the experimental group said in interviews that their reading attitude and learning ability had improved. Positive changes have also taken place in the knowledge level and teaching concept of experimental teachers (Zeng, 2016). Dai (2012) believes that reading is the foundation for improving other English language skills. Fang (2010) believes that students should read widely and effectively in today's information age. The above researchers discuss the necessity and significance of reading in students' life-long development. Therefore, it is very important to improve students' reading ability and show students correct reading methods and skills. The present situation of middle school students' English reading has been studied from different perspectives. The questions mainly focus on the following aspects: bored attitude, shortage of vocabulary, slow language speed and poor grammar foundation, which are the main factors that affect students' reading. Li (2010) believes that from the students' point of view, the textbooks are outdated and the way of asking questions is not new. Fang (2010) believes that the traditional reading teaching method has a far-reaching impact on the reading teaching in China, one of the problems remains - the backward concept and single method. The reasons for the low efficiency of English reading teaching in middle schools are that the vocabulary teaching lacks of originality, reading classroom lacks interactions and cultural atmosphere. Ruan sums up the present situation and reasons of the low efficiency of reading teaching from the perspective of teachers. Most English teachers teach reading by analyzing the grammatical structures of new words, important phrases, long sentences and difficult sentences. This kind of teaching method does not pay attention to the cultivation of students' reading ability. At the same time, he also pointed out that some teachers have not done enough research on teaching materials, reading lessons are not 
supported by schools, reading form is monotonous, the atmosphere is dull, students are not interested in reading.

\subsection{Limitations of Previous Studies}

Based on the literature review mentioned above, previous studies have focused on the dimensions of reading attitude, reading achievement and seldom researches study how to cultivate reading attitude. Also, nowadays, students' reading is usually limited in textbooks and exercise books, which can't arouse students' interest. In addition, teacher's teaching thought, relatively old-fashioned, pays attention to language knowledge transmission but neglects the language skill training, thus causing the student's generally low reading level. However, there are few studies investigating the effects of reading materials on learners' reading. This article aims to explore the relationship between graded reading and students' reading attitude and ability.

\section{Methodology}

\subsection{Research Questions}

The study aims to investigate the correlation between reading materials and learner's reading attitude and ability. Thus, the research questions are as follows:

1) Can graded reading cultivate students' positive reading attitude?

2) Can graded reading help students improve their reading level?

\subsection{Data Collection}

\subsubsection{Subjects}

This paper selects 75 students from two parallel classes in No. 1 Middle School of Liantang in Nanchang. Class 3 is an experimental class with 39 students (20 boys and 19 girls) and Class 5 is a control class with 36 students (19 boys and 17 girls). The experimental group used Oxford graded reading materials, under the guidance of teachers for a semester of reading course training. The control group adopted the traditional teaching method to teach reading.

\subsubsection{Research Tools}

This paper uses questionnaires and personal interviews as research tools to study whether the series-guided reading method can improve students' reading attitude and reading level or not.

\subsubsection{Questionnaire Survey}

The questionnaire is from 'A study of influence of literature circles on senior high school students' attitude towards English reading, which consisted of 30 questions in three dimensions: cognition, emotion and behavioral tendency. The participants answered the questions with a 5-point Likert scale, rating their answers from "totally disagree" to "totally agree", to investigate the reading status and reading level of students.

Before using the questionnaire, we analyzed the reliability and validity of the questionnaire with SPSS (24.0).

Table 1. Reliability of the questionnaire

\begin{tabular}{lll}
\hline Variables & Number of Items & Cronbach's alpha \\
\hline Cognitive Dimensions & 10 & .907 \\
Emotional Dimensions & 10 & .913 \\
Behavior tendency Dimensions Dimensions & 10 & .849 \\
\hline
\end{tabular}

Table1 reveals the Cronbach's alpha coefficient is from 0.849 to 0.913 , indicating the questionnaire gets a high reliability.

Table 2. Validity of the questionnaire

\begin{tabular}{lll}
\hline Kaiser-Meyer-Olin Measure of Sampling Adequacy & Sphericity df & Sig \\
\hline .805 & 36 & .000 \\
\hline
\end{tabular}

Table 2 demonstrates the value of KMO was $0.805(\mathrm{P}<0.001)$, thus it is fit to do exploratory factor analysis. The sig valve is 0.000 , which rejected the null hypothesis. Therefore, the questionnaire has good validity. 


\subsubsection{Pre-Test and Post Test.}

Both pre-test and post test were designed by experienced teachers to avoid subjective factors influencing the results. The pretest used the reading section of the 2017 High School English entrance exam to find out whether there were differences in reading levels between the experimental and control classes. The Post test used the reading section of the 2018 High School English entrance exam to explore whether there were significant differences in reading levels between the two classes after graded reading instruction.

\subsubsection{Personal Interview}

After the questionnaire, the author randomly selected six students to conduct in-depth interviews to study the students' views on the Oxford graded readings. The main questions are:

1) Do you think the Oxford series graded reading has helped you and have you made any progress in reading?

2) Will you continue reading this kind of series reading materials?

\subsubsection{Research Process}

The experimental group chose the Oxford series as the reading material. In addition to the normal English class, the experimental group received a one-semester reading course with a weekly reading session of 45 minutes. Reading material in first week is a simple character story, the second week is life story. With the increase of reading time, the difficulty of reading materials also increases.

\subsubsection{Teaching Procedures for Experimental Group}

Firstly, teacher choose appropriate material for readers. Then, teacher invites students to skim the information of the cover and catalog. Using the information to guess what they are going to read. In this way, students can select interesting reading content.

Here are the strategies the teacher use:

Step 1: Effective guidance: The teacher uses the pictures, songs and videos related to the story to attract the students' attention and let them read the relevant reading materials.

Step 2: Group discussion: After the students have a general idea of the reading material, they will discuss the relevant content and some questions connected with the real life, teacher will join in either.

Step 3: Ask relevant questions: During the reading process, the teacher will ask questions related to the text, such as description, make a list, how you feel, your point of view, to the life experience...

Step 4: Step by step: After completing the first topic, the teacher will ask the students to read the second passage. As the background knowledge of the text is similar to that of the previous passage, the difficulty of reading the second passage will be significantly reduced and the reading level will be improved. Students are then encouraged to read the same type of text. Because there are fewer problems with reading, students don't get frustrated and they'll read faster. The most important thing for students is that they can accumulate a large number of words and phrases from the same topic.

Step 5: After class reading: After class, students are asked to read other articles and write a reading note. There is no limit to the content. Students can write anything they are interested in: their favorite parts, the main idea of the article, etc. The teacher also regularly checks students' reading notes to make sure they have actually finished their reading and invites them to share with other students.

Step 6: Evaluation: There was no reading test during the experiment, but students should evaluate themselves according to their actual reading time and situation. Students should fill in the assessment form every week, so that teachers can master the students' reading situation according to the student's weekly assessment form.

\subsubsection{Data Collection and Analysis}

The research subject must fill in the questionnaire according to the actual situation. In order to ensure the validity of the questionnaire, the students are not required to fill in their names and are not given time for discussion. Then, the author uses SPSS (24.0) to analyze the questionnaire data and independent sample t-test will be used to study whether the graded reading method can help students improve their reading level or not.

\subsection{Procedures of Data Analysis}

\subsubsection{Changes in Students' Reading Attitude}

At the end of the experiment, a questionnaire survey was conducted to find out the change of students' reading attitude. 
Table 3. Descriptive statistics of the questionnaire after experiment

\begin{tabular}{lllll}
\hline \multirow{3}{*}{ Pre-test } & & N & Mean & SD \\
& Class 3 & 39 & 2.175 & 0.67 \\
\multirow{3}{*}{ Post-test } & Class 5 & 36 & 2.133 & 0.43 \\
& Class 3 & 39 & 2.822 & 0.59 \\
& Class 5 & 36 & 2.261 & 0.45 \\
\hline
\end{tabular}

Table 3 shows the results of the descriptive analysis of the questionnaire. We can see that the average pre-test score of the experiment class was 2.175, control class was 2.133, there was no obvious difference between two classes. But after the experiment, the average score of the experimental class rose to 2.822 , while that of the control class was 2.261. The difference between the two classes was significant.

Table 4. Paired sample T-test

\begin{tabular}{lllll}
\hline & Mean & $\mathrm{t}$ & $\mathrm{df}$ & Sig. (2-tailed) \\
\hline pre-test & .1818 & .690 & 54 & .517 \\
Post-test & -6.881 & -9.12 & 54 & .001 \\
\hline
\end{tabular}

Table 4 shows that sig value in pre-test was $0.517>0.05$, and there was no significant difference between the two classes. After the experiment, the sig value was $0.001<0.05$, and there was significant difference between the two classes. As a result, the Oxford series of reading guide can make students have a more positive reading attitude.

\subsubsection{Changes in Students' Reading Level}

Table 5. Descriptive statistics of reading ability

\begin{tabular}{lllll}
\hline \multirow{3}{*}{ Pre-test } & Class & N & Mean & SD \\
& Class 3 & 39 & 17.38 & 8.27 \\
\multirow{3}{*}{ Post-test } & Class 5 & 36 & 17.78 & 9.34 \\
& Class 3 & 39 & 26.10 & 10.6 \\
& Class 5 & 36 & 20.11 & 8.91 \\
\hline
\end{tabular}

As can be seen from Table 5, the average score of the experimental class in the pre-test was 17.38, the control class was 17.78, the average score of the experimental class in the post-test was 26.1 , and the control class was 20.11. It can be seen that, compared with the control class, the average score of the experimental class has been greatly improved after the experiment. However, whether there is a significant difference between the two classes in reading level or not, the independent sample t-test should be used to test the average scores of the two classes.

Table 6. Independent sample t-test

\begin{tabular}{llllll}
\hline & & \multicolumn{4}{l}{$\mathrm{t}$-test for Equality of Means } \\
\cline { 3 - 6 } & $\mathrm{t}$ & $\mathrm{df}$ & $\mathrm{Sig}$. (2-tail) & Mean Diff. \\
\hline pre-test & Equal variances assumed & .1967 & 73 & .885 & -.39316 \\
Post-test & Equal variances assumed & 2.6391 & 73 & .01022 & 5.99145 \\
\hline
\end{tabular}

From Table 6, the sig valve in pre-test of experiment group was $0.885>0.05$, and there was no significant difference between the two classes. After the experiment, the sig value was $0.01022<0.05$, and there was significant difference between the two classes. Therefore, graded reading guidance method can improve students' reading level.

\subsubsection{Personal Interviews}

In the personal interview, the author interviewed 6 students, including two excellent students, two middle students, two students with poor grades. The interview took place in teacher's office. At first, students were little nervous and restrained, but after teachers' communication, students gradually relaxed and were willing to 
participate in the experiment. The following is part of the interview:

Excellent student A: I think this kind of graded reading is very effective and interesting. I will continue to read this series and even recommend it to other friends.

Middle student B: I like English and want to improve my reading skills, but sometimes there are so many new words in reading that it takes much time to look them up in the dictionary. However, in the graded reading class, I have acquired some reading skills to help me with my reading. I like this set of publications, although sometimes I can not understand them, but I will try to keep reading.

Poor Student C: I do not have sense of achievement when reading, and gradually lose confidence in English reading. There are so many new words in this publication that I can't read them very well.

Poor student D: I am good at sporting, but poor at learning English. However, I want to learn English, this set of publications illustrated with pictures, very interesting, I will continue to read and try my best to overcome obstacles.

According to the interviews, most of the students said they had been afraid of reading comprehension and often felt anxious about it, but after reading the graded materials, they found that reading was not as boring as before. One of the students said that he is very interested in English reading at present, and can interact with students in class, he also feels more confident. But one student still said that Oxford books were of little help. Most of the students said they would continue to read the series after the experiment, because they could understand it, unlike reading book or test that would cause stress and anxiety.

Through personal interviews, it can be seen that students are very interested in the Oxford series reading, which can cultivate students' positive reading attitude, and have made progress in reading, and students will continue to read the series after the experiment.

\section{Discussion}

\subsection{Discussion of Question 1}

The results revealed that there was no significant difference in reading attitude between the experimental Class and the control Class before the experiment, but there was a significant difference after the experiment.

This may due to the traditional teaching method will bring greater pressure on students. As a result of exam-oriented education in China, English reading accounts for a larger proportion in the examination, which causes the aim of students' reading is to pursue marks, to train reading strategies, to improve reading scores. This kind of reading will bring pressure to students, causing students' negative reading attitude. The use of Oxford reading materials will develop students' reading skills, which can also effectively arouse students' interest. First of all, the reading material is the real context of some famous story rather than boring text, when students meet the topic that they are interested with, their reading interest will be effectively stimulated. Secondly, the task of reading teaching under the guidance of series books is diversified, instead of completing the questions, students don't have to worry that their answers are correct or not, because there is no standard answer. Finally, performance is not the only evaluation criterion. In the traditional reading teaching, the evaluation standard is usually based on the result, but the series guidance method pays attention to the process evaluation, and students' enthusiasm will not be reduced with the decrease of the scores, which is helpful to cultivate students' reading attitude.

Moreover, according to schema theory, readers' reading ability and comprehension of materials depend on three schemata: linguistic schemata, content schemata and formal schemata. In the teaching of graded reading, the teacher selects suitable reading materials for the students, which adapt to the students' current linguistic schemata and awakens the existing schemata. The variety of the theme and content in the reading material enriches the students' content schema, and the unique structure of the story also helps to arouse the students' reading interest and change the students' reading attitude.

\subsection{Discussion of Question 2}

Before the experiment, there was no significant difference between experimental group and controlled group, but after the experiment, the average score of experimental group was higher than that of controlled group, which proved that graded reading is beneficial to students reading capacity.

The reasons are as follows: First of all, according to krashen's affective filter hypothesis, learners' affective factors have a certain impact on second language acquisition. If the learner's learning goal is clear and his learning attitude is positive, then his learning motivation is stronger, his affective filter is weaker, learning effect will be better, and vice versa. Under the method of graded reading, the teacher creates a harmonious and relaxed 
classroom atmosphere, reduces the students' negative affective filter. At the same time, students' reading attitude is positive, and they have the willingness to learn, so they can produce better reading effect. Secondly, under the graded reading teaching method, students have more opportunities to communicate with others and express themselves. They can exchange the reading information between teachers and their peers. In this process, not only the reading skills can be trained, but also the students' expressive ability can be improved in this process, students can effectively acquire and produce language, reading level can be improved.

\section{Conclusion}

\subsection{Major Findings of the Study}

The graded reading method can cultivate students' positive reading attitude. When the pressure of examination is relatively low, students can read the interesting reading materials and acquire the relevant reading contents and skills under the guidance of teachers. At the same time, communication and sharing with peers can improve students' reading interest. Therefore, in the future reading teaching, English teachers should create a relaxed situation to carry out interesting reading teaching, choose reading books that attract students' interest, and implement open, cooperative and communicative learning to cultivate students' positive reading attitude.

Secondly, under the graded reading method, the student's reading level can be enhanced remarkably. Thus, in the future teaching, teachers can flexibly combine in-class reading and after-class reading, paying attention to the guidance of students in the teaching process, and consciously carrying out reading training for students, so as to improve students' reading level.

\subsection{Limitations and Suggestions for Further Study}

At the same time, this paper still has some limitations. First of all, this study only selects two middle school English classes of 75 students; the sample size is relatively small. Whether the findings apply to high school students or college students remain to be seen. Second, the experimental time only last for one semester, while the development of students' reading attitude needs a long time, so it needs more time to study the change of students' reading attitude. The future research may proceed from these aspects to carry out research.

\section{Acknowledgement}

I am deeply grateful to my supervisor, it was his patient advice that my paper can be finished.

\section{References}

Azmmddin, R. A., \& Zuraina, A. (2017). Extensive reading project using graded readers in a university classroom. Centre for Modern Language and Human Science.

Chow, B. W., \& Chui, B. H. (2017). Creative literacy activities promote positive reading attitude in children learning English as a foreign language. Journal of Research in Reading, 41(2), 278-289. https://doi.org/10.1111/1467-9817.12096

Dai, Y. (2012). The importance of strengthening English reading. English Study, 12, 110.

Fang, F. (2010). Effective ways to improve students reading ability in junior English teaching. Education and Teaching Forum. https://doi.org/10.3969/j.issn.1674-9324.2010.10.124.

Fang, Y. J. (2010). Reflection and discussion on the teaching of English reading in middle school. Journal of Ningbo University.

Feng, B. (2012). A survey of junior high school students' English reading ability and the Educational Research and comments on the related teaching suggestions. Junior Education and Teaching.

Gillian, C. (2012). Graded readers: How the publishers make the grade. Reading in a Foreign Language, 24(1), $106-119$.

Godeman, K. S. (1967). Reading: A Psycholinguistics Guessing Game. Journal of the Reading Specialist, 6(4), 126-135. https://doi.org/10.1080/19388076709556976

Jimmy, G., \& Sean, K. (2019). How effective are early grade reading interventions? A review of the evidence. Educational Research Review. https://doi.org/10.1596/1813-9450-8292

Jonathan, M. S. B., Anna, D., \& Margaret, M. (2017). Using Early Grade Reading Assessment (EGRA) data for targeted instructional support: Learning profiles and instructional needs in Indonesia. International Journal of Educational Development, 61, 64-71.

Mori, S. (2004). Significant motivational predictors of the amount of reading by EFL learners in Japan. RELC Journal, 35(4), 63-81. https://doi.org/10.1177/003368820403500106 
Neil, J. A. (2003). Schemata in school language reading. The Reading Matrix, 2(3), 14-27.

Nigel, S. (2001). Helping ESL students become better readers: Scheme theory application and limitations. The Internet TESL Journal.

Ramirez, G., Fries, 1., Gunderson, E., Schaeffer, M. W., Maloney, E. A., Bellock, S. L., \& Levine, S. C. (2019). Reading anxiety: An early affective impediment to children's success in reading. Journal of Cognition and Development, 20(1), 15-34. https://doi.org/10.1080/15248372.2018.1526175

Ruan, Q. J. (2011). Teaching methods of English reading teaching in middle school. Educational Journal, 8(1), 109-110. https://doi.org/10.3969/j.issn.1672-1578.2011.01.081

Rumelhart, D, E., \& Ortony, A. (1977). The representation of knowledge in memory. In R. C. Anderson, R. J. Spiro, \& W. E. Montague (Eds.), Schooling and acquisition of knowledge. New York: Academic press. https://doi.org/10.4324/9781315271644-10

\section{Copyrights}

Copyright for this article is retained by the author, with first publication rights granted to the journal.

This is an open-access article distributed under the terms and conditions of the Creative Commons Attribution license (http://creativecommons.org/licenses/by/4.0/). 